\title{
CONDUCTION DISORDERS AND PERMANENT CARDIAC PACEMAKER AFTER TRANSCATHETER AORTIC IMPLANTATION - AN UPDATE OVERVIEW
}

\author{
Prof. Antonio da Silva Menezes Junior, PhD ${ }^{1 凹}$ (D), Marcelo de Freitas Ribeiro ${ }^{2} \square$ (iD), Tiago de

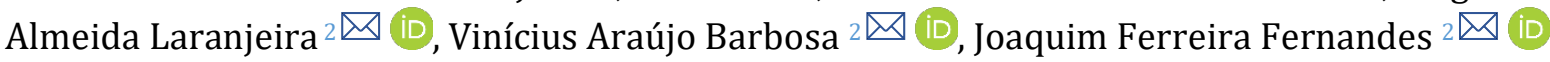 \\ ${ }^{1}$ MD and Associate Professor, School of Medicine, Federal University of Goiás and Pontificial Catholic \\ University, Goiás, Brazil. \\ ${ }^{2}$ Scholar, School of Medicine, Pontifical Catholic University, Goiás, Brazil.
}

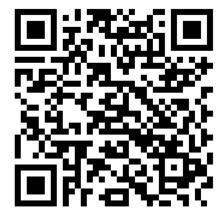

Received 1 August 2021

Accepted 12 August 2021

Published 31 August 2021

\section{CorrespondingAuthor}

Prof. Antonio da Silva Menezes Junior, PhD, a.menezes.junior@uol.com.br

DOI

10.29121/granthaalayah.v9.i8.2021. 4110

Funding: This research received no specific grant from any funding agency in the public, commercial, or not-for-profit sectors.

Copyright: (C) 2021 The Author(s). This is an open access article distributed under the terms of the Creative Commons Attribution License, which permits unrestricted use, distribution, and reproduction in any medium, provided the original author and source are credited.

\section{ABSTRACT}

Aortic valve substitution is a standard technique with tolerable risk; nevertheless, the high mortality may be contraindicated. To reduce morbidity and mortality minimally invasive transcatheter aortic valve implantation (TAVI) may be an alternative approach. Although considered secure, after the method complications can occur, presenting as new-onset persistent left bundle branch block and demanding pacemaker implant. To establish how frequent this probability is, a systematic review from PUBMED (philters used were "15 years" and "free full texts") was achieved applying the terms "TAVI", "pacing" and "complications". For supporting literature, the other sources (SCIELO, Google Scholar and MEDLINE) were used

and consulted for supporting literature. Catheter aortic prosthesis implantation is an effective modality for patients with high surgical risk and severe aortic stenosis. The review results suggest that the need for a pacemaker after endovascular treatment is neither inevitable nor easily predicted by known risk factors. Even though TAVI is considered a safe technique of selection, the implant position is near to functionally significant septal cardiac structures. Conduction disorders are frequent and need prudent checking after the procedure. Forthcoming studies must be necessary to validate the proposed algorithm and define the role of EP studies, ambulatory continuous electrocardiogram (Holter 24 hours) monitoring and preventive pacemaker in the management of conduction disturbances in patients undergoing transcatheter aortic valve replacement.

Keywords: Transcatheter Aortic Valve Implantation; Aortic Valve Stenosis; Cardiac Pacing; Complications

\section{INTRODUCTION}

The most frequent valvular heart disease is aortic stenosis (AS). It involves $2 \%$, $3 \%$ and $4 \%$ of elderly over 65,75 and 85 years correspondingly, and the frequency appears to increase in intensity as the population ages Bajrangee A, Coughlan JJ, Teehan S, et al. 2017. It is an insidious disease with a long latency period, known to develop rapidly after the beginning of symptoms, heading to a high proportion of deaths in untreated patients Leon MB, Smith CR, Mack M, et al. 2010, Lemos PA, Mariani J, Esteves Filho A, et al. 2010, Junior ASM, de Oliveira PPC, Almeida LF, et al. 2018. 
Transcatheter aortic valve implantation (TAVI) is a less invasive alternative to surgical aortic valve replacement (SAVR) in patients with severe AS, who either cannot undergo surgery or are at intermediate/high surgical risk Yokoyama $\mathrm{H}$, Tobaru T, Muto Y, et al. 2019, Kolkailah AA, Doukky R, Pelletier MP, Volgman AS, Kaneko T, Nabhan AF 2019, Popma JJ, Deeb GM, Yakubov SJ, Mumtaz M, Gada H, et al. 2019.

Once a bioprosthetic valve is introduced through a catheter and installed within the injured natural aortic stenotic valve is a procedure named TAVI Leon MB, Smith CR, Mack M, et al. 2010. It is an option conventional surgery for patients with severe AS, who have an enhanced threat of surgery. It additionally increases patient survival and quality of life Monteiro C, Ferrari ADL, Caramori PRA, et al. 2017. Nowadays, despite this new technology, surgical valve replacement is the treatment of choice for symptomatic severe AS Lemos PA, Mariani J, Esteves Filho A, et al. 2010 and Junior ASM, de Oliveira PPC, Almeida LF, et al. 2018.

There are more than a few valve models that can be implanted percutaneously at the aortic level; but most procedures in the literature use the "Edwards SAPIEN prosthetic heart valve" and the "CoreValve ReValving System" Piazza N, de Jaegere P, Schultz C, et al. 2008. The Edwards SAPIEN has a balloon inflatable stainless steel cylindrical rim to which is sewn a three-leaflet equine biological pericardial heart valve and a material skirt to attenuate paravalvular aortic regurgitation. The SAPIEN $^{\mathrm{TM}}$ THV uses a stainless-steel frame and is available in two sizes: outer diameters of 23 and $26 \mathrm{~mm}$ and heights of 14.3 and $16.1 \mathrm{~mm}$, respectively, when fully deployed. The newer SAPIEN XT ${ }^{\mathrm{TM}}$ THV is made of a cobalt-chrome frame; the strength of the alloy is greater and make available for a decrease in strut thickness with fewer stent struts, causing in a compliment device for introduction. As a result, radial strength may be lower. It is available in four sizes, with outer diameters of 20 , 23, 26 and $29 \mathrm{~mm}$ and heights of 13.5, 14.3, 17.2 and $19.1 \mathrm{~mm}$ respectively Figure 1.

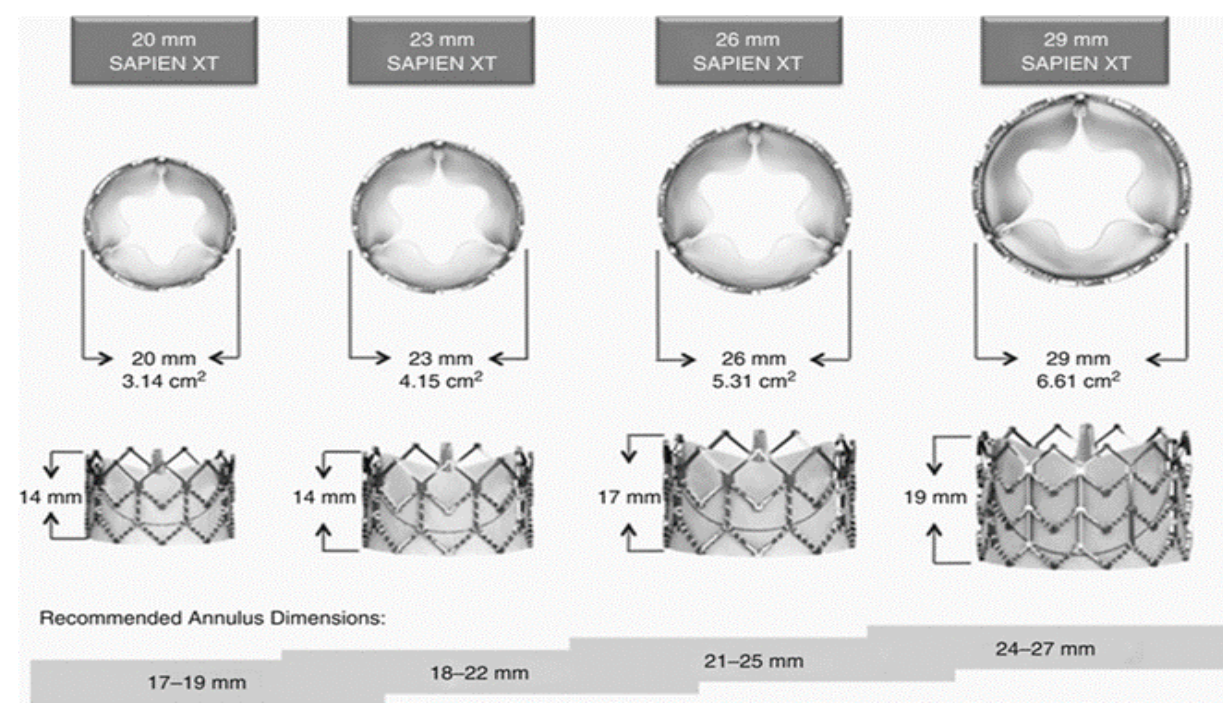

Figure 1 Edwards SAPIEN XT dimensions and recommended annulus sizes. Image taken from 'A Transcatheter Aortic Valve Replacement: A Cardiac Surgeon and Cardiologist Team Perspective', 2010. 
It is expected that around one third of patients with the feature AS are postponed from surgical treatment since the high risk of postoperative mortality Lemos PA, Mariani J, Esteves Filho A, et al. 2010. TAVI is now "the standard of care for patients at high surgical risk or inoperable patients with severe AS," Bajrangee A, Coughlan JJ, Teehan S, et al. 2017 and Junior ASM, de Oliveira PPC, Almeida LF, et al. 2018. It allows percutaneous implantation of a novel aortic valve with standard procedures via the transfemoral approach under local anaesthesia, alternatively with transapical, transaortic and subclavian approaches - depending on the patient's vascular anatomy.

In general, these next-generation valves are self-expanding and have features that can facilitate valve positioning and improve annular sealing, as well as lower profile delivery systems to allow for smaller vessel diameters. These valves are currently in clinical trials, and it remains unclear whether outcomes will be inferior, comparable, or superior to current generation THVs Figure 2 Bajrangee A, Coughlan JJ, Teehan S, et al. 2017. TAVI is now "the standard of care for patients at high surgical risk or inoperable patients with severe AS," Bajrangee A, Coughlan JJ, Teehan S, et al. 2017.

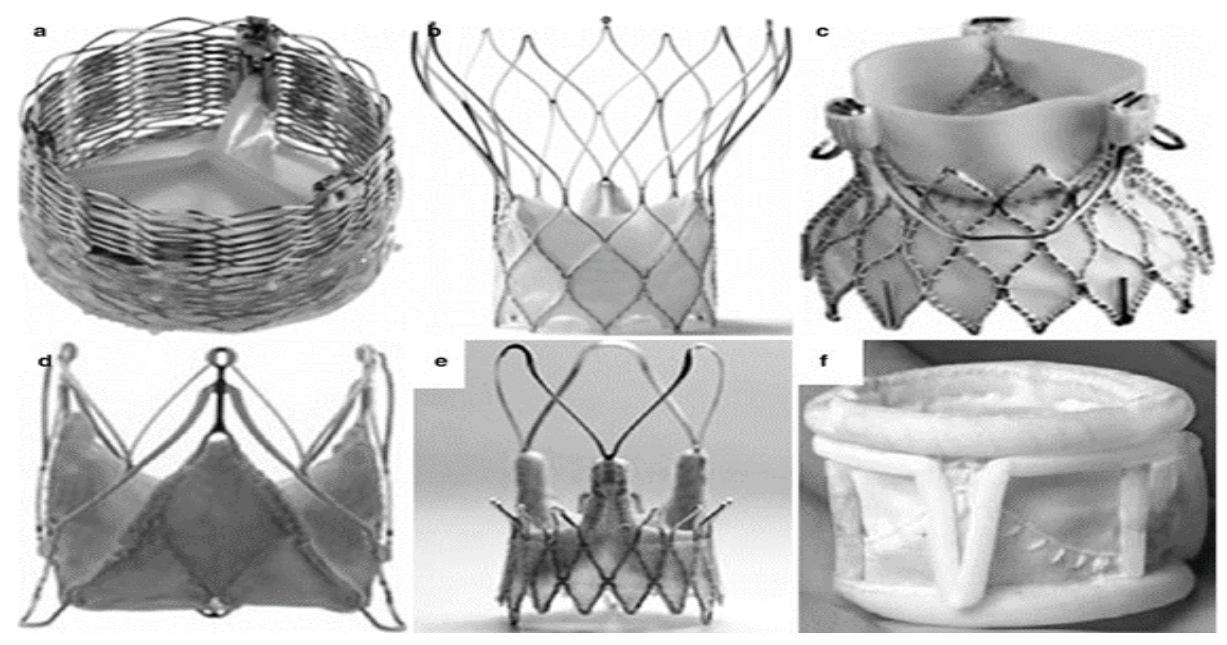

Figure 2 Newer transcatheter heart valves under evaluation: (a) Lotus valve (Boston Scientific Inc., USA), (b) Portico valve (St. Jude Medical Inc., USA), (c) Engager valve (Medtronic Inc., USA), (d) JenaClip valve (JenaValve Inc., DE), (e) Acurate valve (Symetis Inc., $\mathrm{Ch}$ ), and (f) Direct Flow valve (Direct Flow Medical Inc., USA).

According to Sarmento-Leite R, De Quadros AS, Prates PRL, et al. 2009 the components of the cardiac conduction system, the valve ring and adjacent structures were compressed by the area near to the valve covered by the endoprosthesis. The atrioventricular node and the left branch of the His bundle pass within the fibrous body may be affected by the device because they are adjacent to the non-coronary cusp of the aortic valve Sarmento-Leite R, De Quadros AS, Prates PRL, et al. 2009, Perin MA, Sândoli de Brito F, Oliveira Almeida B, Pereira MAM, et al. 2009

Conduction defects and permanent pacemaker implantation (PPMI) remain a common and important consequence of transcatheter aortic valve replacement (TAVR). Understanding risk factors for TAVR-related conduction disorders could improve patient selection, procedural techniques and periprocedural efforts to monitor and treat heart block Tsoi M, Tandon K, Zimetbaum PJ, Frishman WH. 2021. Several studies have identified patient-related and procedural factors associated 
with new-onset left bundle branch block, high-grade atrioventricular block and the need for PPMI after TAVR. Notable patient-related predictors include pre-existing right bundle branch block, membranous septal length and calcification of the left ventricular outflow tract. Modifiable procedural predictors include device implantation depth, prosthesis oversize and valve type Monteiro C, Ferrari ADL, Caramori PRA, et al. 2017.

Although mortality and rates of serious problems have decreased with newer generation valves, rates of pacemaker implantation and conduction disturbances continue high with both self-expandable (SE) and balloon-expandable (BE) valves Thyregod HG, Steinbrüchel DA, Ihlemann N, et al. 2015, Ben-Shoshan J, Konigstein M, Zahler D, et al. 2017, Webb J, Gerosa G, Lefevre T, et al. 2014, Kolkailah AA, Doukky R, Pelletier MP, Volgman AS, Kaneko T, Nabhan AF. 2019, Popma JJ, Deeb GM, Yakubov SJ, Mumtaz M, Gada H, et al. 2019. In addition, there are reports of the advancement of delayed conduction abnormalities and late complete atrioventricular block (CAVB) Tovia-Brodie O, Michowitz Y, Belhassen B. 2020.

\section{MATERIALS AND METHODS}

\section{Eligibility criteria}

A systematic literature search was conducted in PUBMED using "15 years" and "free full texts" as filters and with the keywords "TAVI", "TAVI AND pacing" and "TAVI AND complications" to identify eligible articles. There were no language restrictions. A total of 11 articles were carefully chosen from this search. To ensure background, consistency, and depth of text other databases such as SCIELO, Google Scholar and MEDLINE were used.

\section{Inclusion and exclusion criteria}

Articles that did not address complications occurring after TAVI placement and articles that centered on pre-existing genetic factors or diseases and aggravation of complications were rejected. This search may contain publication bias as it only reviews freely available articles. Therefore, it is necessary that additional studies are performed and related to those shown here Figure 3.

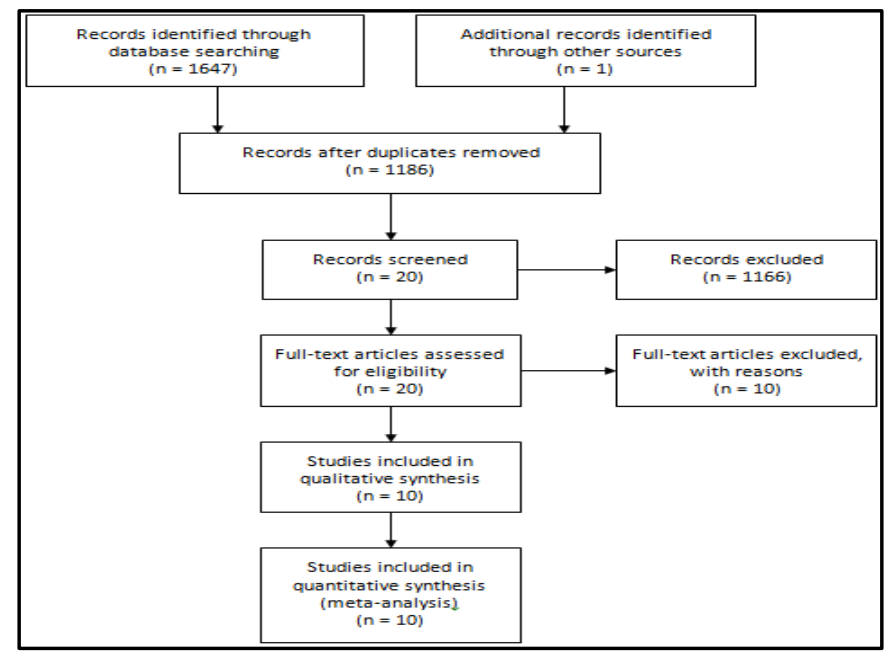

Figure 3 Flow chart of studies selection 


\section{RESULTS AND DISCUSSIONS}

The literature search firstly found 1648 significant titles from PUBMED, SCIELO, Google Scholar and MEDLINE. Of these, 1186 were removed due to duplicate entries. After reading the titles and abstracts, 20 articles were selected for full reading and 10 were included in the analysis. The study selection process and reasons for exclusion are reviewed in Figure 3.

Based on the analysis of the articles, it was possible to establish the most common complications after TAVI placement. Studies considered a possible association between TAVI and a decrease in coronary flow, which would lead to a myocardial injury reflected by a post-procedural increase in serum troponin I; however, no positive correlation with this finding could be established, as the existence of a reduction in blood pressure retrieval time was only seen in assessment to the duration of rapid pacing Kahlert P, Al-Rashid F, Plicht B, et al. 2016, Junior ASM, de Oliveira PPC, Almeida LF, et al. 2018.

A further complication was found in relation to the occurrence of new-onset and permanent LBBB after TAVI, which often required the implantation of a permanent pacemaker (PPM), but this did not increase the mortality rate of patients. The studies point to the need for careful and prolonged surveillance for the PPM indication during follow-up and to assess the impact of persistent LBBB on recent initiation (Tomo et al., 2019; Marina Urena M and Josep Rodés-Cabau M. 2015, Akin I, Kische S, Paranskaya L, et al. 2012, Popma JJ, Deeb GM, Yakubov SJ, Mumtaz M, Gada H, et al. 2019, Mack MJ, Leon MB, Thourani VH, Makkar R, Kodali SK, et al. 2019, Thyregod HG, Steinbrüchel DA, Ihlemann N, et al. 2015, Ben-Shoshan J, Konigstein M, Zahler D, et al. 2017, Webb J, Gerosa G, Lefevre T, et al. 2014, Barbanti M, Buccheri S, Rodés-Cabau J, et al. 2017, Tovia-Brodie O, Michowitz Y, Belhassen B. 2020, RodésCabau J, Ellenbogen KA, Krahn AD, et al. 2019, Tsoi M, Tandon K, Zimetbaum PJ, Frishman WH. 2021, Junior ASM, de Oliveira PPC, Almeida LF, et al. 2018.

Based on the reviewed scientific literature, the criteria used to determine whether to place a PPM include (a) complete atrioventricular (AV) block with recent onset; (b) new Mobitz Type II AV block; (c) new LBBB with prolongation of the PR interval; (d) new LBBB with atrial fibrillation with slow ventricular response; and (e) transient asystole during the procedure.

Most patients requiring PPM placement are older (81\%) and male (59.3\%) - they are the ones who spend the most time in hospital due to complications of transcatheter aortic valve implantation Lemos PA, Mariani J, Esteves Filho A, et al. 2010. Hospital length of stay may increase if there was prior "...right bundle branch block (RBBB), use of a CoreValve prosthesis and a basal transaortic gradient of 50 mmHg" Monteiro C, Ferrari ADL, Caramori PRA, et al. 2017. Patients who had any of the above factors were $63 \%$ more likely to need PPM compared to $4 \%$ in patients who had none of these predictors.

Ventricular atrial block (AV) has been found to be another conduction abnormality caused by TAVI placement and may be related to "...higher incidence of mortality, SCD and left ventricular dysfunction" as noted by Hamdan A, Guetta V, Klempfner R, et al. 2015. The same study also found that high-grade AV block occurred in $18 \%$ of patients analyzed in $1.2 \pm 1.1$ days after TAVI, with $29 \%$ undergoing PPM implantation in $2.2 \pm 2.1$ days Junior ASM, de Oliveira PPC, Almeida LF, et al. 2018. 
Lemos PA, Mariani J, Esteves Filho A, et al. 2010 was the only article to address the expansion of severe aortic regurgitation of the prosthetic valve 16 months after TAVI. To resolve the question, a CoreValve Evolut $\mathrm{R}$ prosthesis was implanted directly above the LV -edge of the JenaValve used. The treatment option applies to the transvalvar defect made explicit in the case.

To better understand what was found in the review, a table was created with the main articles used and their main points, such as title, year of publication, authors, journal and a preview of the conclusion and main points of the results Table 1.

\begin{tabular}{|c|c|c|c|}
\hline SOURCE & DESIGN & YEAR & MAIN RESULTS \\
\hline $\begin{array}{l}\text { Kahlert P, Al- } \\
\text { Rashid F, } \\
\text { Plicht B, et al. } \\
2016\end{array}$ & Clinical trial & 2015 & $\begin{array}{l}\text { There were no significant correlations between } \\
\text { coronary flow dynamics, CFVR and AUC over } 72 \text { hours, } \\
\text { between the amount of HITS and TnI AUC, in patients } \\
\text { with transfemoral TAVI. }\end{array}$ \\
\hline $\begin{array}{l}\text { Marina Urena } \\
\text { M and Josep } \\
\text { Rodés-Cabau } \\
\text { M. } 2015\end{array}$ & Clinical trial & 2015 & $\begin{array}{l}\text { The rate of LBBB after TAVI and the rate of permanent } \\
\text { pacemaker (PPM) are around } 27 \% \text { and } 17 \% \text {, } \\
\text { correspondingly. The incidence of reimplantation of } \\
\text { LBBB and PPMI is higher after using the self-expanding } \\
\text { CoreValve system (Medtronic Inc.; Minneapolis, MN, } \\
\text { USA) compared to the balloon-expandable Edwards } \\
\text { SAPIEN / SAPIEN XT valve (Edwards Lifesciences LLC; } \\
\text { Irvine, CA, USA). }\end{array}$ \\
\hline
\end{tabular}

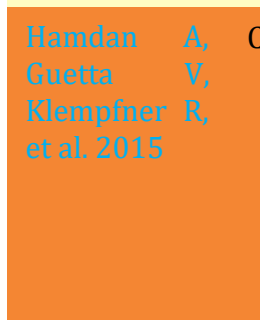

Akin I, Kische

S, Paranskaya

Clinical trial 2015

L, et al. 2012

Clinical trial 2012

Analyses showed MS length as the strongest independent predictor of high-grade AV block and the difference between MS length and depth of implantation as the strongest independent predictor of high-grade AV block. The difference between MS length and depth of implantation and calcification in the basal septum were the strongest independent predictors of MPP implantation.

TAVI was successful in all patients. Baseline ECG and intracardiac EC showed higher QP, longer HA and HV intervals in patients who required a pacemaker than in the control group. Multivariate analysis showed that only the new LBBB, QRS duration $120 \mathrm{~ms}$ and a PQ interval 200 milliseconds immediately (within 60 minutes) after aortic valve implantation were high grade (grade II and III)).

Monteiro C, $\quad$ Clinical trial 2017
Ferrari ADL,
Caramori
PRA, et al.
2017

Leon MB, Clinical trial 2010
Smith CR,
Mack M, et al.
$2010 \quad$

Thirty days after TAVI, $20.1 \%$ of patients required a PPMI. These patients were approximately 82 years old and most patients were male. Length of hospital stay was higher in those who underwent PPMI; however, PPMI was not associated with all causes of death, nor with deaths of cardiovascular etiology. CoreValve $₫$ prosthesis and basal transaortic gradient $50 \mathrm{~mm} \mathrm{Hg}$ were predictors of PPMI.

All-cause mortality, at one-year, was inferior with TAVI $(30.7 \%)$ related to standard therapy $(50.7 \%)$, the rate of cardiac symptoms (New York Heart Association class III or IV) was lower in patients with TAVI than in

\section{CONCLUSION}

Myocardial injury after TAVI due to the hypoperfusion-induced ischemia more accurately than periprocedural microembolization.

Due to the high incidence of complications associated with TAVI implantation, such as conduction disorders and the need for PPM, there are major concerns about its use. However, the use of a balloon-expandable valve at a more aortic implantation site may reduce these complications.

Short MS, insufficient difference between MS length and implantation depth and the presence of calcifications in the basal septum may occur after placement of TAVI with selfexpandable valves.

Cardiac dysfunction, especially conduction, is common after TAVI placement. Sometimes the need for a pacemaker is unavoidable.

RBBB, mean aortic gradient 50 $\mathrm{mmHg}$ and CoreValve ${ }^{\circledR}$ are independent predictors of MPD implantation after TAVI. MPD implantation occurred in approximately $20 \%$ of TAVI cases, which prolonged hospital stay but had no effect on mortality.

TAVI reduced mortality from any cause in patients with severe AS who were not suitable for surgery compared to standard therapy. 
those receiving standard therapy, and there was no deterioration in biological prosthesis function.

Bajrangee A, Clinical trial $2017 \quad \begin{aligned} & \text { In } 147 \text { predominantly male patients with an average } \\ & \text { age of } 82 \text { years who underwent TAVI, survival rates at } \\ & \text { Coughlan JJ, }\end{aligned}$
$\begin{aligned} & \text { 70 days, one year and two years were } 90.5 \%, 83 \% \text { and } \\ & \text { in the first month were renal failure and major vascular } \\ & \text { complications. }\end{aligned}$

Popma JJ, Clinical trial 2019 A total of 1468 patients were randomized and 1403 Deeb GM,

Yakubov SJ,

Mumtaz M,

Gada $\mathrm{H}$, et al.

2019

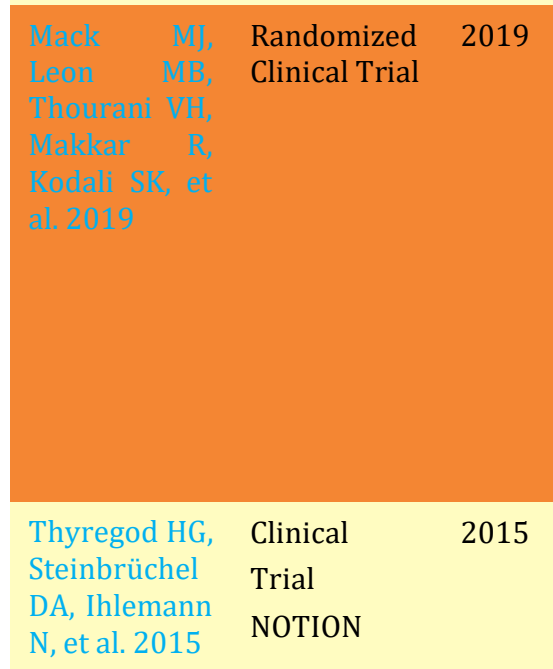
patients was 74 years. The estimated 24-month underwent TAVR or surgery. The mean age of the incidence of the primary endpoint was $5.3 \%$ in the TAVR group and $6.7 \%$ in the surgical group (difference $=-1.4$ percentage points; $95 \%$ Bayesian credibility interval for difference $=-4.9$ to 2.1 ; posterior probability of non-inferiority 0.999). At 30 days, compared with surgery, patients who underwent TAVR had a lower incidence of disabling stroke $(0.5 \%$ vs. $1.7 \%)$, bleeding complications $(2.4 \%$ vs. $7.5 \%)$, acute kidney injury $(0.9 \%$ vs. $2.8 \%)$ and atrial fibrillation (7.7\% vs. 35.4\%) and a higher incidence of moderate or severe aortic regurgitation $(3.5 \%$ vs. $0.5 \%)$ and pacemaker implantation $(17.4 \%$ vs. $6.1 \%)$. At 12 months, patients in the TAVR group had lower aortic valve gradients ( $8.6 \mathrm{mmHg}$ vs. $11.2 \mathrm{mmHg}$ ) and larger effective orifice areas $(2.3 \mathrm{~cm} 2$ vs. $2.0 \mathrm{~cm} 2)$ than patients in the surgery group.

At 71 centers, 1000 patients underwent randomization. The average age of the patients was 73 years. At 30 days, TAVR resulted in a lower rate of stroke $(\mathrm{P}=0.02)$ and a lower rate of death or stroke $(\mathrm{P}$ $=0.01$ ) and new-onset atrial fibrillation (P 0.001) than surgery. TAVR also resulted in a shorter index hospitalization than surgery (P 0.001) and a lower risk of poor treatment outcome (death or a low Kansas City Cardiomyopathy Questionnaire score) at 30 days $(\mathrm{p}<0.001)$. There were no significant differences between groups in serious vascular complications, new permanent pacemaker insertions or moderate or severe paravalvular regurgitation.

A total of 280 patients were randomized at 3 Nordic centers. The mean age was 79.1 years, and $81.8 \%$ were classified as low-risk patients. No significant difference was found in the primary endpoint in the intention-totreat population $(13.1 \%$ vs. $16.3 \%$; $p=0.43$ for superiority). The result did not change in the as-treated population. No difference was found in the rate of cardiovascular death or prosthesis reintervention. Compared with SAVR-treated patients, TAVR-treated patients had more conduction abnormalities requiring pacemaker implantation, greater improvement in effective orifice area, greater total aortic valve regurgitation, and higher New York Heart Association functional class at 1 year. SAVR-treated patients had more severe or life-threatening bleeding, cardiogenic shock, acute renal failure (stage II or III) and new-onset or worsening $\mathrm{AF}$ at 30 days than TAVR-treated patients.
Through this review, it was possible to verify favourable survival rates 30 days, one year and two years after cessation of TAVI. Procedural success and complication rates were similar to those reported internationally.

In patients with severe AS, who were at low surgical risk, TAVR with a self-expanding supraannular bioprosthesis was non-inferior to surgery for the composite endpoint of death or disabling stroke at 24 months.

In patients with severe AS, who were at low surgical risk, the composite rate of death, stroke or rehospitalization at 1 year was significantly lower with TAVR than with surgery.

In the NOTION study, no significant difference was found for the composite rate of death from any cause, stroke or MI at 1 year between TAVR and SAVR. (Nordic Aortic Valve Intervention Trial [NOTION] 


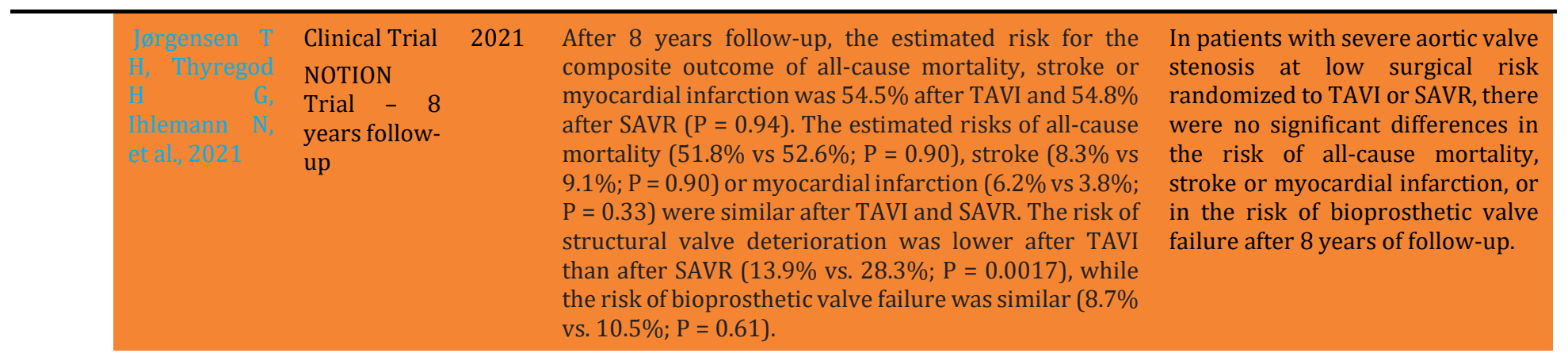

CFVR = coronary flow velocity reserve; AUC = area under the curve of TnI; HITS = high-intensity transient signals; MS = membranous septum.

According to Akin I, Kische S, Paranskaya L, et al. 2012, when considering the risk factors for complete AV block after surgical valve replacement, "prior aortic regurgitation, pulmonary hypertension, myocardial infarction, and postoperative electrolyte imbalance are the main risk factors. The strongest predictor of the need for a pacemaker is RBBB on surface ECG." In TAVI, the overall local impairment is influenced by factors such as calcification at the surgical site, height of the implantation site in the left ventricular outflow tract, intensity of the trauma that occurred during the procedure (balloon valvuloplasty, balloon to aortic annulus ratio and post-TAVI dilatation) and aortic annulus geometry. TAVI could be performed safely and effectively in nonagenarians with acceptable long-term outcomes compared to younger patients, although attention should be paid to major vascular complications as seen in Figure 4 by Yokoyama H, Tobaru T, Muto Y, et al. 2019.

In 2020, TAVI has been recognized as one of the most important revolutionary therapies in modern medicine due to the PARTNER3 Mack MJ, Leon MB, Thourani VH, Makkar R, Kodali SK, et al. 2019 and EVOLUT LOW RISK Popma JJ, Deeb GM, Yakubov SJ, Mumtaz M, Gada H, et al. 2019 clinical trials and is indicated for low-risk patients (STS 4\%). The PARTNER3 trial, conducted in 71 centers with patients with a mean age of 73 years and an STS of $1.9 \%$, showed superiority of TAVI for the primary composite endpoint (death, stroke and rehospitalization) at one-year follow-up. The secondary endpoints showed a lower incidence of new AF within 30 days, lower hospitalization rates and more effective control of heart failure-related symptoms (according to the KCCQ score and the 6-minute walk test).

The EVOLUT LOW RISK study, conducted in patients in the same age range, analyzed the composite endpoint of death and stroke at 24-month follow-up. The study showed a lower incidence of debilitating stroke, acute renal failure, bleedingrelated complications and atrial fibrillation. In contrast, the study showed a higher incidence of moderate to severe aortic regurgitation and an increased need for pacemaker implantation.

According to Kolkailah AA, Doukky R, Pelletier MP, Volgman AS, Kaneko T, Nabhan AF. 2019, three studies reported short- and long-term PPM implantation Popma JJ, Deeb GM, Yakubov SJ, Mumtaz M, Gada H, et al. 2019, Mack MJ, Leon MB, Thourani VH, Makkar R, Kodali SK, et al. 2019, Thyregod HG, Steinbrüchel DA, Ihlemann N, et al. 2015. TAVI probably increased the risk of short-term PPM, and this increased risk persisted in the long term (RR (random effects) $=3.48,95 \% \mathrm{CI}=$ 1.40 to $8.62 ; 2683$ participants; 3 trials; $\mathrm{Tau} 2=0.53$; Chi $2=15.78, \mathrm{df}=2(\mathrm{P}=$ 0.0004); I2 = 87\%; NNTH = 6, 95\% CI = 3 to 48; Analysis 1.17). However, there was observed heterogeneity despite confirmation of data accuracy and absence of 
methodological error. Possible explanations for this heterogeneity may be differences in the populations or interventions of the studies. For example, the valve type used in the TAVI groups differed between studies, with NOTION 2015 Thyregod HG, Steinbrüchel DA, Ihlemann N, et al. 2015 and EVOLUT 2019 Popma JJ, Deeb GM, Yakubov SJ, Mumtaz M, Gada H, et al. 2019 using SE valves, while PARTNER 32019 Mack MJ, Leon MB, Thourani VH, Makkar R, Kodali SK, et al. 2019 used BE valves.

In addition, the NOTION 2015 participants were older on average. We also noted the lower number of events in the surgical arm of NOTION 2015 compared with the other two studies; therefore, we used a random effects model for pooling outcomes. STACCATO 2012 reported 90-day PPM implantation, where two of the 34 participants in the TAVI group had an event, compared with one of the 36 in the SAVR group. NOTION 2015 reported longer-term follow-up for PPM implantation with persistent increased risk in TAVI recipients at two years (TAVI $=41.3 \%$ vs SAVR $=4.2 \%$, log-rank $\mathrm{P} 0.001$ ) and five years (TAVI $=41.7 \%$ vs SAVR $=7.8 \%, \log$ rank P 0.001) Kolkailah AA, Doukky R, Pelletier MP, Volgman AS, Kaneko T, Nabhan AF. 2019.

After 8 years of follow-up Nordic Trial (NOTION 2015), left ventricular ejection fraction was similar between TAVI and SAVR patients and the risk of all-cause mortality was not significant, although numerically higher, in pacemaker-naïve patients who underwent permanent pacemaker implantation within 30 days of TAVI compared with patients without a permanent pacemaker. A lower threshold for prophylactic pacemaker implantation in the early TAVI period may have resulted in a low percentage of pacemakers, potentially attenuating the effects of pacemaker implantation. However, the percentages of pacemakers in the present study were not available to confirm this Jørgensen T H, Thyregod H G, Ihlemann N, et al., 2021, Serruys PW, Piazza N, Cribier A, et al. 2009, Yokoyama H, Tobaru T, Muto Y, et al. 2019.

The rate of more than mild PVL after TAVI was higher in the NOTION study than in current practices, which may be explained in part by the sizing of the aortic annulus, which was performed by echocardiography rather than computed tomography, and the use of primarily first-generation THV without an outer sealing skirt and the possibility of repositioning. Leon MB, Smith CR, Mack M, et al. 2010, Yokoyama H, Tobaru T, Muto Y, et al. 2019. The presence of PVL was not associated with an increased risk of mortality after 8 years of follow-up. Nevertheless, the risk of all-cause mortality was increased in TAVI patients with mild vs. no or trace PVL in the 5-year data from the PARTNER 1 trial $(73.0 \%$ vs. $68.3 \%$; $\mathrm{P}=0.003)$ and the PARNTER 2 trial (48.7\% vs. $41.1 \%$; $\mathrm{P}=0.07$ ).6,8 This trend towards higher mortality in patients with PVL after TAVI may be concerning for younger patients with longer life expectancy Jørgensen T H, Thyregod H G, Ihlemann N, et al., 2021, Chen S, Chau KH, Nazif TM. 2020.

Table 2 Incidence of LBBB and PPM implantation with newer-generation THVs

\begin{tabular}{|ccc|}
\hline Valve Type & Persistent new onset LBBB\% & $\mathbf{3 0}$ day PPM \% \\
\hline SAPIEN 3 & $13-23,5$ & $6,2-20,5$ \\
\hline SAPIEN 3 Ultra & N/A & $4,4-6,4$ \\
\hline EVOLUTR & $20,6-28,6$ & $16,4-25,9$ \\
\hline Evolut PRO & 17,8 & $7,4-17,1$ \\
\hline Lotus Edge & N/A & 20,0 \\
\hline
\end{tabular}




\begin{tabular}{ccc}
\hline Accurate Neo & 10,3 & $3,0-10,0$ \\
Pontico with FlexNov & 28,3 & $9,8-27,7$ \\
JenaValve & N/A & 19,4
\end{tabular}

"Representative studies were limited to those published after 2016 and with a sample size $\geq 100$ (unless only smaller ones were available). KM Estimated event rates from 30-day PPM were presented where possible: (a) rates reported in this study from PPM were not separated by valve type; (b) reported rate is the proportion of patients with new PPM (not KM estimated); (c) patients with PPM or LBBB at baseline (depending on outcome of interest) were excluded. LBBB = left bundle branch block; PPM = permanent pacemaker; $\mathrm{THV}=$ transcatheter heart valve." Source: Chen S, Chau KH, Nazif TM. The incidence and impact of cardiac conduction disorders after transcatheter aortic valve replacement. Ann Cardiothorac Surg. 2020 Nov;9(6):452-467. doi: 10.21037/acs-2020-av-23.

Consequently, continuous follow-up of patients undergoing TAVI is required to identify potential complications and treat possible conduction disorders. However, studies with a much larger cohort of patients are needed to provide definitive data on the risk of delayed life-threatening arrhythmias and sudden death after TAVR especially in those patients who have conduction disorders after the procedure. Indeed, these risk scores may need to consider the type of transcatheter valve (a risk score for each valve may be required). Importantly, the application of a consistent strategy regarding the management of conduction disturbances across multiple centers seems to be the key to establishing reliable arrhythmia risk scores, as seen in Figure 4.

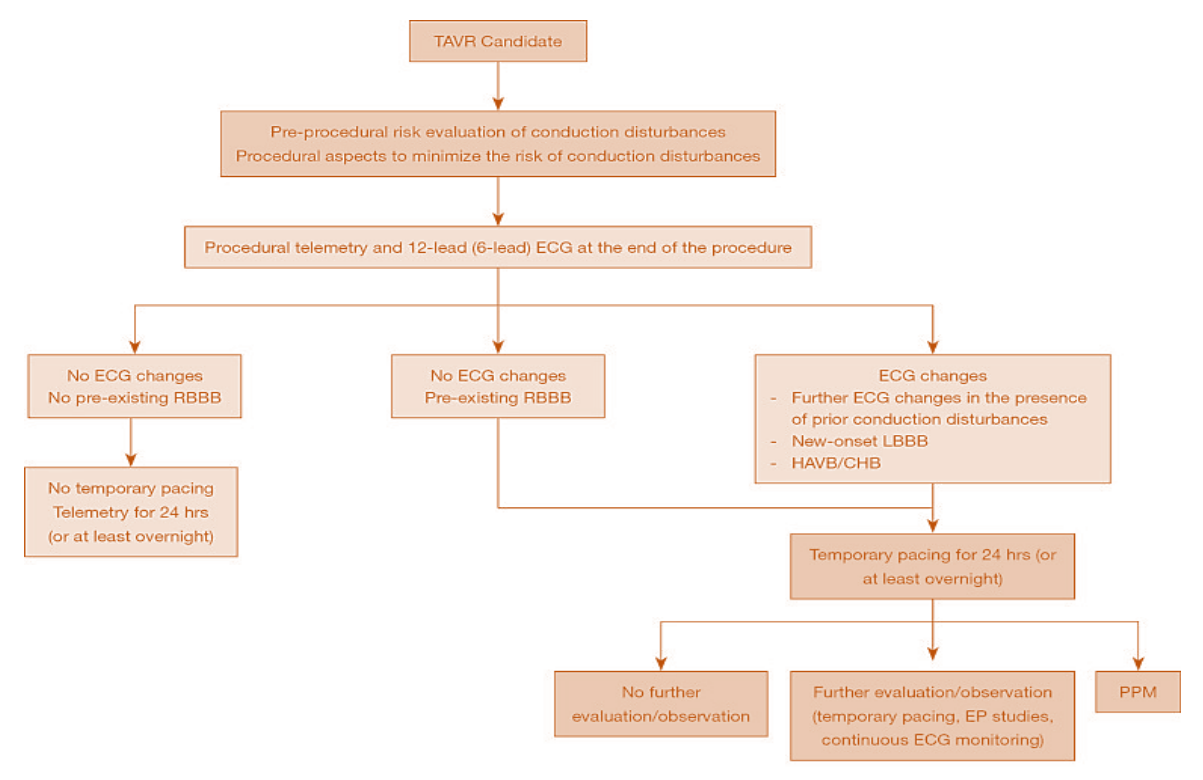

"Consider earlier discontinuation of temporary pacing if regression of ECG changes in $<24 \mathrm{~h}$ (except for pre-existing RBBB).

Figure 4 Expert panel algorithms for the management of conduction disturbances after TAVR. Algorithm illustrates how best to manage conduction disturbances that develop after TAVR. ECG = electrocardiogram; EP = electrophysiology; LBBB = left bundle branch block; PPM = permanent pacemaker; RBBB = right bundle branch block; TAVR = transcatheter aortic valve replacement. Source: RodésCabau et al. (2019) 


\section{CONCLUSIONS AND RECOMMENDATIONS}

Implantation of a prosthetic aortic valve via a catheter is a valid modality for patients at high surgical risk AS. The results of this series of patients suggest that the need for a definitive pacemaker after endovascular treatment is neither unstoppable nor easily predicted by the risk factors described so far. Consequently, the most common complication after TAVI is implantation of a permanent pacemaker.

TAVI is the procedure of choice because it is considered feasible and safe; however, the implantation site of the prosthetic valve is close to septal cardiac structures with important function, and conduction disturbances are common, requiring cautious monitoring for at least seven days after the procedure. There is a lack of consensus and wide variability in the management of conduction disturbances after TAVR. Future studies need to validate the proposed algorithm and determine the role of EP studies, ambulatory continuous ECG monitoring and prophylactic pacing in the management of conduction disturbances in patients after TAVR.

\section{REFERENCES}

Akin I, Kische S, Paranskaya L, et al. 2012. Predictive Factors for Pacemaker Requirement After Transcatheter Aortic Valve Implantation. BMC Cardiovasc Disord.;12:87. Published 2012 Oct 4. Doi :10.1186/1471-226112-87

Ando T, Takagi H 2016; ALICE (All-Literature Investigation of Cardiovascular Evidence) Group. The Prognostic Impact of New-Onset Persistent Left Bundle Branch Block Following Transcatheter Aortic Valve Implantation: A Meta-analysis. Clin Cardiol.;39(9):544-550. Doi :10.1002/clc.22567

Bajrangee A, Coughlan JJ, Teehan S, et al. 2017. Early and Mid-term Outcomes After Transcatheter Aortic Valve Implantation (TAVI) in Ireland. Int J Cardiol Heart Vasc.;16:1-3. Published 2017 Jul 7. Doi: 10.1016/j.ijcha.2017.06.001

Barbanti M, Buccheri S, Rodés-Cabau J, et al. 2017. Transcatheter Aortic Valve Replacement with New-Generation Devices: A Systematic Review and MetaAnalysis. Int J Cardiol.;245:83-89. Doi: 10.1016/j.ijcard.2017.07.083

Ben-Shoshan J, Konigstein M, Zahler D, et al. 2017. Comparison of the Edwards SAPIEN S3 Versus Medtronic Evolut-R Devices for Transcatheter Aortic Valve Implantation. Am J Cardiol; 119:302-7. Retrived from https://doi.org/10.1016/j.amjcard.2016.09.030 ; PMID: 28029363.

Chen S, Chau KH, Nazif TM. 2020. The Incidence and Impact of Cardiac Conduction Disturbances After Transcatheter Aortic Valve Replacement. Ann Cardiothorac Surg. Nov;9(6):452-467. Doi: 10.21037/acs-2020-av-23.

Hamdan A, Guetta V, Klempfner R, et al. 2015. Inverse Relationship Between Membranous Septal Length and the Risk of Atrioventricular Block in Patients Undergoing Transcatheter Aortic Valve Implantation. JACC Cardiovasc Interv.;8(9):1218-1228. Doi: 10.1016/j.jcin.2015.05.010

Junior ASM, de Oliveira PPC, Almeida LF, et al. 2018. Cardiac Pacing and Transcatheter Aortic Valve Implantation (TAVI): A Literature Update Journal of Vascular and Endovascular Therapy . 3(11):1-6. 
Jørgensen T H, Thyregod H G, Ihlemann N, et al., 2021. Eight-year outcomes for patients with aortic valve stenosis at low surgical risk randomized to transcatheter vs. surgical aortic valve replacement, European Heart Journal,; 43(30): 2912-2919, Retrived from https://doi.org/10.1093/eurheartj/ehab375

Kahlert P, Al-Rashid F, Plicht B, et al. 2016. Myocardial Injury During Transfemoral Transcatheter Aortic Valve Implantation: An Intracoronary Doppler and Cardiac Magnetic Resonance Imaging Study. EuroIntervention.;11(12):1401-1408. Doi :10.4244/EIJY15M05_10

Kolkailah AA, Doukky R, Pelletier MP, Volgman AS, Kaneko T, Nabhan AF. 2019. Transcatheter Aortic Valve Implantation Versus Surgical Aortic Valve Replacement for Severe Aortic Stenosis in People with Low Surgical Risk. Cochrane Database Syst Rev. 2019;12(12):CD013319. Published Dec 20. Doi: 10.1002/14651858.CD013319

Lemos PA, Mariani J, Esteves Filho A, et al. 2010. Transcatheter Aortic Valve Implantation Without Permanent Pacemaker in a Series of Consecutive Cases: Is it Possible to Predict the Risk of Atrioventricular Block? Rev Bras Cardiol Invasiva;18(2):135-9.

Leon MB, Smith CR, Mack M, et al. 2010. Transcatheter Aortic-Valve Implantation for Aortic Stenosis in Patients who Cannot Undergo Surgery. N Engl J Med.;363(17):1597-1607. Doi :10.1056/NEJMoa1008232.

Mack MJ, Leon MB, Thourani VH, Makkar R, Kodali SK, et al. 2019. PARTNER 3 Investigators. Transcatheter Aortic-Valve Replacement with a BalloonExpandable Valve in Low-Risk Patients. N Engl J Med. May 2;380(18):16951705. Doi: 10.1056/NEJMoa1814052.

Marina Urena M and Josep Rodés-Cabau M. 2015. Managing Heart Block After Transcatheter Aortic Valve Implantation: From Monitoring to Device Selection and Pacemaker Indications. Euro Interv;11 Suppl W: W101-5. Doi :10.4244/EIJV11SWA30

Monteiro C, Ferrari ADL, Caramori PRA, et al. 2017. Permanent Pacing After Transcatheter Aortic Valve Implantation: Incidence, Predictors and Evolution of Left Ventricular Function. Arq Bras Cardiol.109(6):550-559. Doi : $10.5935 / a b c .20170170$

Perin MA, Sândoli de Brito F, Oliveira Almeida B, Pereira MAM, et al. 2009. Percutaneous Aortic Valve Replacement for the Treatment of Aortic Stenosis: Early Experience in Brazil. Arquivos Brasileiros de Cardiologia;;93(3):299-306.

Piazza N, de Jaegere P, Schultz C, et al. 2008 Anatomy of the Aortic Valvar Complex and its Implications for Transcatheter Implantation of the Aortic Valve. Cardiovascular Interventions;; Vol. 1, Circulation:74-81.

Popma JJ, Deeb GM, Yakubov SJ, Mumtaz M, Gada H, et al. 2019 . Evolut Low Risk Trial Investigators. Transcatheter Aortic-Valve Replacement with a SelfExpanding Valve in Low-Risk Patients. N Engl J Med. May 2;380(18):17061715. Doi :10.1056/NEJMoa1816885.

Rodés-Cabau J, Ellenbogen KA, Krahn AD, et al. 2019. Management of Conduction Disturbances Associated With Transcatheter Aortic Valve Replacement: 
JACC Scientific Expert Panel. J Am Coll Cardiol.;74(8):1086-1106. Doi: 10.1016/j.jacc.2019.07.014.

Ruel M, Labinaz M. 2010. Transcatheter Aortic-valve Replacement: a Cardiac Surgeon and Cardiologist Team Perspective. Curr Opin Cardiol.;25(2):107113. Doi: $10.1097 /$ HCO.0b013e328335ff4

Sarmento-Leite R, De Quadros AS, Prates PRL, et al. 2009. Marca-passo Permanente após Implante Percutâneo Valvular Aórtico: A Necessidade é Maior Que Imaginávamos? Rev Bras Cardiol Invasiva;17(4):476-83.

Serruys PW, Piazza N, Cribier A, et al. 2009. Transcatheter Aortic Valve Implantation, Tips and Tricks to Avoid Failure. 1st ed. Boca Raton, Florida: CRC Press; p. 113-114.

Thyregod HG, Steinbrüchel DA, Ihlemann N, et al. 2015 . Transcatheter Versus Surgical Aortic Valve Replacement in Patients With Severe Aortic Valve Stenosis: 1-Year Results From the All-Comers NOTION Randomized Clinical Trial. J Am Coll Cardiol. May 26;65(20):2184-94. Doi: 10.1016/j.jacc.2015.03.014.

Tovia-Brodie O, Michowitz Y, Belhassen B. 2020. Use of Electrophysiological Studies in Transcatheter Aortic Valve Implantation. Arrhythm Electrophysiol Rev. Jun 3;9(1):20-27. Doi: 10.15420/aer.2019.38.3.

Tsoi M, Tandon K, Zimetbaum PJ, Frishman WH. 2021. Conduction Disturbances and Permanent Pacemaker Implantation after Transcatheter Aortic Valve Replacement: Predictors and Prevention [published online ahead of print, Jun 14]. Cardiol Rev. 2021;10.1097/CRD.0000000000000398. Doi :10.1097/CRD.0000000000000398

Webb J, Gerosa G, Lefevre T, et al. 2014. Multicenter Evaluation of a Next-Generation Balloon-Expandable Transcatheter Aortic Valve. Am J Coll Cardiol; 64:223543. Doi: org/10.1016/j.jacc.2014.09.026.

Yokoyama H, Tobaru T, Muto Y, et al. 2019 Long-term Outcomes in Japanese Nonagenarians Undergoing Transcatheter Aortic Valve Implantation: A Multi-center Analysis. Clin Cardiol. 42(6):605-611. Doi: 10.1002/clc.23183. 